\title{
Assessment of climate change impact on hydrological extremes in two source regions of the Nile River Basin
}

\author{
M. T. Taye ${ }^{1}$, V. Ntegeka ${ }^{1}$, N. P. Ogiramoi ${ }^{1,2}$, and P. Willems ${ }^{1}$ \\ ${ }^{1}$ Katholieke Universiteit Leuven, Hydraulics Division, Kasteelpark Arenberg 40, 3001 Leuven, Belgium \\ ${ }^{2}$ Directorate of Water Development, Rural Water Department, Ministry of Water and Environment, \\ P.O. Box 20026, Kampala, Uganda
}

Received: 28 July 2010 - Published in Hydrol. Earth Syst. Sci. Discuss.: 9 August 2010

Revised: 15 January 2011 - Accepted: 18 January 2011 - Published: 20 January 2011

\begin{abstract}
The potential impact of climate change was investigated on the hydrological extremes of Nyando River and Lake Tana catchments, which are located in two source regions of the Nile River basin. Climate change scenarios were developed for rainfall and potential evapotranspiration (ETo), considering 17 General Circulation Model (GCM) simulations to better understand the range of possible future change. They were constructed by transferring the extracted climate change signals to the observed series using a frequency perturbation downscaling approach, which accounts for the changes in rainfall extremes. Projected changes under two future SRES emission scenarios A1B and B1 for the 2050s were considered. Two conceptual hydrological models were calibrated and used for the impact assessment. Their difference in simulating the flows under future climate scenarios was also investigated.

The results reveal increasing mean runoff and extreme peak flows for Nyando catchment for the 2050s while unclear trend is observed for Lake Tana catchment for mean volumes and high/low flows. The hydrological models for Lake Tana catchment, however, performed better in simulating the hydrological regimes than for Nyando, which obviously also induces a difference in the reliability of the extreme future projections for both catchments. The unclear impact result for Lake Tana catchment implies that the GCM uncertainty is more important for explaining the unclear trend than the hydrological models uncertainty. Nevertheless, to have a better understanding of future impact, hydrological models need to be verified for their credibility of simulating extreme flows.
\end{abstract}

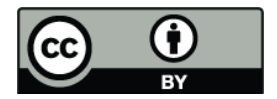

Correspondence to: $\mathrm{M}$. T. Taye (meronteferi.taye@bwk.kuleuven.be)

\section{Introduction}

Climate change impact studies associated with global warming as a result of an increase in greenhouse gases (GHG) has been given ample attention worldwide in the recent decades. The advancements in climate models have increased confidence in the outputs required as inputs for hydrological applications. This has spurred many hydrological climate change impact studies (e.g. Booij, 2005; Xu et al., 2005; Andersson et al., 2006; and Jiang et al., 2007). However, hydrological impact studies ought to receive more attention as there are still grey areas related to the interfacing of climate and hydrological models. Moreover, given the potential projections of droughts and floods (IPCC, 2007), vulnerable hydrological resources are too important to defer the climate change investigations.

The Nile River is a water resource which is already under immense pressure due to various competitive uses as well as social, political and legislative conditions. Further, previous studies show that many parts of the Nile basin are sensitive to climatic variations (Conway and Hulme, 1996; Yates and Strzepek 1996, 1998a, b; Conway, 2005; Kim et al., 2008; Beyene et al., 2010) implying that climate change will have a considerable impact on the resource. Therefore, it is necessary to analyse the possible changes in the different water resources aspects under the changing climatic conditions. However, due to variable climatic regions this impact might not be similar throughout the basin. Hence, dividing the basin into different regions will be a convincing and proficient approach when studying impact of climate change.

Potential impact of climate change in the Nile basin has been studied using outputs from General Circulation Models (GCMs) by different researchers on different catchments

Published by Copernicus Publications on behalf of the European Geosciences Union. 
of the basin during the previous years (Conway and Hulme, 1993, 1996; Strzepek and Yates, 1996; Conway 2005; Kim et al., 2008; Beyene et al., 2010; Elshamy et al., 2009a, b; Elshamy and Wheater, 2009; Soliman, et al., 2008; Githui et al., 2009). The studies used different methods for translating specified changes in climatic inputs into changes in hydrological regimes. Bias correction and applying monthly changes were among some of the methods used to generate the climate series. Afterwards, hydrological models were used to generate the hydrological regimes. For example, Elshamy et al. (2009a) used bias corrected statistical downscaling method to analyze outputs of 17 GCMs and to construct downscaled scenarios while Kim et al. (2008) applied the change factor method using monthly totals to construct the future climate variables. Beyene et al. (2010), states that most of the previous studies were limited by the coarse spatial resolution of the GCMs used and the small number of GCMs that could be evaluated. In addition, the impact of using different hydrological models for a given climate change scenario is not widely investigated and reported in literature for the Nile basin. Nevertheless, this kind of investigation is important. For instance, a study by Jiang et al. (2007) showed greater differences in impact of climate change on water availability in the Dongjiang basin in South China, when different hydrological models were used for the same climate scenarios. It is also crucial that models are tested for their performance in describing/predicting extreme hydrological conditions. Projection of climate change impacts on hydrological extremes (floods, droughts, or water scarcity) is however of major importance for the region. Therefore, this paper attempted to evaluate the performance of two hydrological models in projecting climate change impact on the mean hydrology of selected catchments in the Nile basin.

The investigation of the potential impact of climate change on the hydrology and hydrological extremes considers the use of many GCM runs to provide a wider range of uncertainty in the GCM based climate projections. It is very crucial to assess the capacity of these climate models' outputs to simulate the past or present day climate over the selected region of interest before applying them for impact assessment studies. GCMs can be evaluated using different methods such as geostatistical techniques for spatial variability (Booij, 2002), correlations between variables for internal consistency (Wilby and Wigley, 2000), and multidecadal variability for evaluating the natural variability of the models (Delworth and Mann, 2000) among others. This study applied statistical analysis to ascertain whether mean climate and the extreme quantiles are simulated correctly. The Root mean squared error (RMSE) and bias were used to check the simulation of the mean climate while frequency analysis was used to check the models' ability to simulate extreme conditions.

Linking the coarse spatial resolution climate models with hydrological models requires downscaling techniques to provide catchment scale climate scenarios for rainfall and poten-

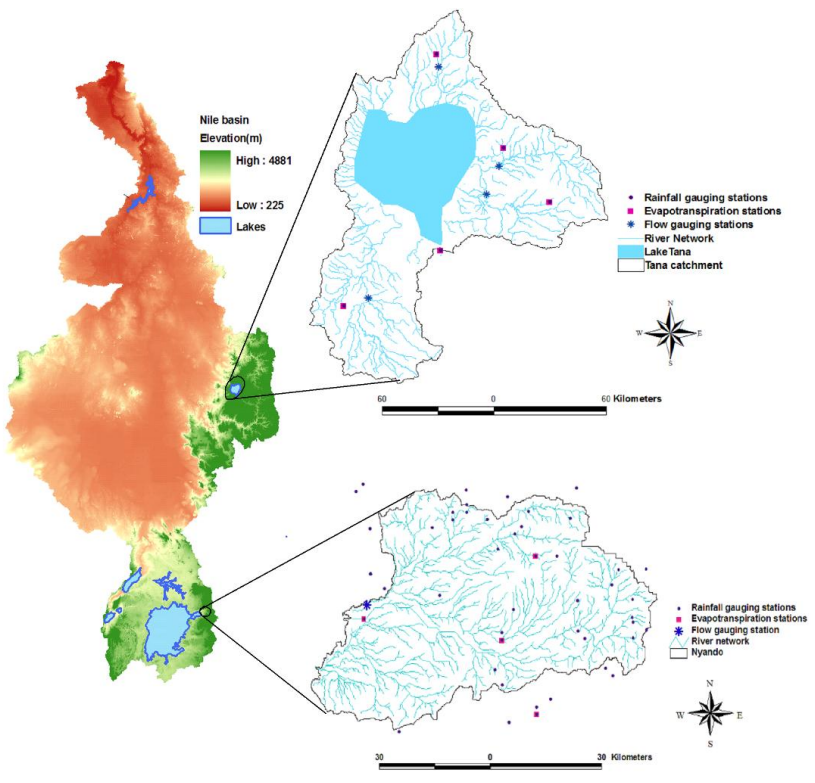

Fig. 1. The Nile basin (left) and meteorological and flow gauging stations in Lake Tana catchment (top, right) and Nyando catchment (bottom, right).

tial evapotranspiration (ETo) as input to hydrological models. In this paper, a frequency perturbation downscaling approach is used. This approach provides predictions consistent with the occurrence of wet days and wet day intensities for rainfall and intensities for ETo. The intensities are perturbed in relation to their frequency of occurrence. In this way, each intensity is perturbed with a unique factor.

The study aims to investigate the potential impact of climate change on the hydrology and hydrological extremes of two catchments in the Nile basin using two different hydrological models forced with outputs from 17 GCM runs and two SRES (Special Report on Emission Scenarios) emission scenarios.

\section{Study area and data}

Two catchments were selected from the Nile basin. Nyando catchment with an area of about $3600 \mathrm{~km}^{2}$ located in the Equatorial lakes region and entirely lies in Western Kenya, between $34.80^{\circ} \mathrm{E}$ and $35.75^{\circ} \mathrm{E}$ longitude and $0.15^{\circ} \mathrm{N}$ and $0.45^{\circ} \mathrm{S}$ latitude. Lake Tana catchment with an area of $15000 \mathrm{~km}^{2}$, located between $36.89^{\circ} \mathrm{E}$ and $38.25^{\circ} \mathrm{E}$ longitude and $10.95^{\circ} \mathrm{N}$ and $12.78^{\circ} \mathrm{N}$ latitude, the source of Blue Nile, from the Ethiopian highlands (Fig. 1).

Nyando catchment has a sub-humid climate with mean annual temperature of $23^{\circ} \mathrm{C}$ and mean annual rainfall varying from $1000 \mathrm{~mm}$ near Lake Victoria to over $1600 \mathrm{~mm}$ in the highlands. The annual rainfall pattern shows no distinct dry season. It is tri-modal with peaks during the long rains (March-May) and short rains (October-December) with the 
third peak in August. The rainfall is controlled by the northward and southward movement of the Inter-Tropical Convergence Zone (ITCZ) (Muthusi et al., 2005).

The climate of Lake Tana is of "tropical highland monsoon" type with one rainy season between June and September and a dry season from October to March. The air temperature shows large diurnal but small seasonal changes with an annual average of $20^{\circ} \mathrm{C}$ (Setegn et al., 2008). The seasonal distribution of rainfall is controlled by the northward and southward movement of the ITCZ. Moist air masses are driven from the Atlantic and Indian Oceans during summer (June-September). During the rest of the year the ITCZ shifts southwards and dry conditions persist in the region between October and May.

Although these two basins are classified under the subhumid/humid climates, their rainfall patterns are rather different. For this reason, this research attempts to ascertain the differences in climate change projections and consequently their potential impact on the hydrology of the two source regions of the Nile basin: equatorial lakes region upstream of the White Nile and Lake Tana region upstream of the Blue Nile.

\subsection{Data}

For hydrological modelling of the catchments, five years daily data (1976-1980) were used for calibration of Nyando river catchment and the period 1986-1990 for validation. Similarly, the period 1992-1995 was used for calibration of Lake Tana catchment and the period 1996-1998 for validation. It would have been better to use similar periods, however, it was not possible due to data unavailability. The input rainfall and ETo data were calculated as weighted average time series from point measurements using the Thiessen polygon method. FAO Penman-Monteith method (Allen et al., 1998) was used for estimating ETo. Due to lack of data for all the required climatic inputs, the FAO PenmanMonteith method of estimating ETo with limited data was applied in the research. The method estimates the other variables (radiation, wind speed, relative humidity, and air pressure) based on the observed maximum and minimum temperature in the catchments and from their geographical locations.

For Nyando, the weighted average rainfall was calculated using 38 stations in and around the catchment, while four stations were used for the weighted average ETo computation (Fig. 1). In the case of Lake Tana catchment, five point stations were used to calculate both weighted average rainfall and ETo daily time series (Fig. 1). The availability of data determined the number of stations used for the analysis. It is important to mention that for the climate model evaluation, only one station in each catchment was used for calculating the biases.

For developing climate scenarios, the observed meteorological daily datasets for rainfall, maximum and minimum temperature for both catchments under study were obtained from specific meteorological stations within the catchments. The period 1961-2000 was taken as the baseline period that represents the current condition, while the 2050s (20462065) were considered for the future climate scenario. Observed daily meteorological datasets were collected from the Kisumu station, representing the Nyando catchment for the period 1971-1990; and Bahir Dar station, representing the Lake Tana catchment for the period 1991-2000.

Daily climate model (GCM) data for rainfall, maximum and minimum temperature was extracted from the IPCC AR4 database archived at the Program for Climate Model Diagnosis and Intercomparison (PCMDI). The future GHG emission scenarios $\mathrm{A} 1 \mathrm{~B}$ and $\mathrm{B} 1$ were considered to cover a wider range of projection. The global warming for the 2050s indicates that $\mathrm{A} 1 \mathrm{~B}$ and $\mathrm{B} 1$ are the high and low scenarios respectively. From the climate models that were available selection was made with GCM runs which had both rainfall and temperature simulations for control and future scenario periods.

\section{Materials and methods}

\subsection{Hydrological modelling}

The models used for simulating the river flows are lumped conceptual hydrological models, namely VHM and NAM. The models are calibrated individually for each catchment. VHM is a Dutch abbreviation for "generalized lumped conceptual and parsimonious model structure identification and calibration" following the procedure developed by Willems (2011). NAM is the Danish "Nedbør-Afstrømnings-Model", a lumped conceptual precipitation-runoff-model developed by DHI Water and Environment (DHI, 2008).

\subsubsection{VHM approach}

The VHM approach works through a step-wise modelstructure identification procedure (Willems, 2011). The necessary input time series are rainfall and potential evapotranspiration averaged over the catchment. The rainfall-runoff model calibration requires time series pre-processing of the available daily river flow series prior to its calibration. The required flow time series pre-processing are:

1. Hydrological sub-flow separation (quick flow, interflow and slow flow),

2. Split of the time series in nearly independent quick and slow flow events, and

3. Extraction of nearly independent high and low flow extremes from historical flow records in the catchment.

In a first step, the river flows were separated in their runoff sub-flows based on the extended Chapman filter method described in Willems (2009). The Nyando river flow was separated into three components (slow flow, interflow and quick 


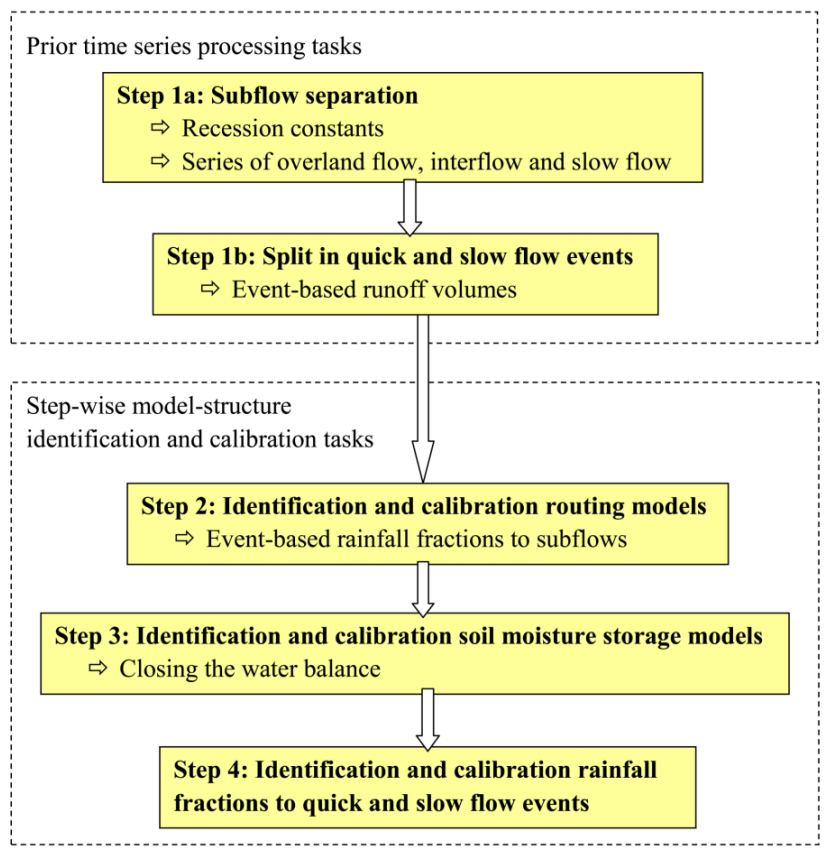

Fig. 2. Steps in the VHM model structure identification and calibration procedure (adapted from Willems, 2011).

flow). In the case of Lake Tana catchment, the filtering was limited to only two components, the slow flow and quick flow components. In the next steps, all significant peak and low flow events were extracted for both catchments. This involved separation of the flow series in nearly independent quick and slow flow periods (Willems, 2009) and selection of the maximum flow during each quick flow period (as peak flow event) and the minimum flow during each slow flow period (as low flow event). See Willems (2009) for more details on the method of these time series processing techniques.

With the above described river flow time series preprocessing, information is extracted that can be used to identify and calibrate the main hydrological catchment responses and storages. Storage elements are considered representing the surface, unsaturated zone and groundwater storage. These storages are combined with reservoir models to describe the routing of the sub-flows. Relations are identified between the rainfall fraction that per event contributes to the separated sub-flows and other hydrological variables. These relations represent sub-models describing soil storage, quick flow, interflow and slow flow volumes. The sub-model structure identifications and calibrations are done by matching the modelled fraction values with the ones estimated from the sub-flow filtering. The steps of model structure identification and calibration procedure are presented as flow diagram in Fig. 2.

The underlining equations used for calibrating both catchments are described hereafter. The first and most important sub-model that needs identification and calibration in the
VHM approach is the soil water storage model. The appropriate storage model was evaluated by plotting the storage fraction of precipitation versus the soil water state. For both catchments, the exponential model, which has a mathematical relation as Eq. (1), gave good results. The soil moisture storage volume is emptied by the actual evapotranspiration, which is a fraction of potential evapotranspiration as per Eqs. (2) and (3). Depending on the soil storage results, the quick flow and interflow fractions of precipitation were analyzed. Exponential models were identified for both catchments which have mathematical relations as Eq. (4).

$f_{u}=c_{1}-\exp \left(c_{2}\left(\frac{u}{u_{\max }}\right)^{c_{3}}\right)$

where: $u$ is soil water depth

$u_{\max }$ is maximum soil water capacity

$c_{1}, c_{2}$ and $c_{3}$ are model coefficients

$f_{u}$ is rainfall fraction to soil water storage

$e_{\mathrm{a}}=e_{p} \quad\left(u>u_{\text {evap }}\right)$

$e_{\mathrm{a}}=\frac{u}{u_{\mathrm{evap}}} e_{p} \quad\left(u \leq u_{\text {evap }}\right)$

where: $e_{\mathrm{a}}$ is actual evapotranspiration

$e_{p}$ is potential evapotranspiration

$u_{\text {evap }}$ is threshold value for $u$, above which $e_{\mathrm{a}}$ becomes equal to $e_{p}$

$f_{i, o}=\exp \left(\left(c_{1}+c_{2} \frac{u}{u_{\max }}\right)+\left(c_{3}+c_{4} \ln r\right)\right)$

where: $r$ is antecedent rainfall (previous day)

$c_{1}, c_{2}, c_{3}$ and $c_{4}$ are model coefficients

$f_{i, o}$ is rainfall fraction to interflow or overland flow

\subsubsection{NAM model}

Similar to VHM the NAM model was set up with observed series of rainfall and ETo averaged over the catchments. In this case, the model structure was fixed, with three storage elements, surface, root zone and groundwater storages, and linear reservoir models describing overland, inter- and baseflow. Figure 3 describes the model structure of NAM. The model considers moisture intercepted on the vegetation, water trapped in depressions and in the uppermost, cultivated part of the ground as surface storage. This storage is continuously diminished by evaporative consumption as well as by horizontal leakage (interflow). When there is a maximum surface storage, some of the excess water, will enter the streams as overland flow, whereas the remainder is diverted as infiltration into the lower zone and groundwater storage. The model equations can be found in DHI (2008).

Model parameters were determined by manual, trial-anderror calibration against the observations. The calibration method for NAM could not be the same as VHM as the modelling philosophies of the two models are different. Thus, the classical two step process of calibration and validation was followed for NAM model. 


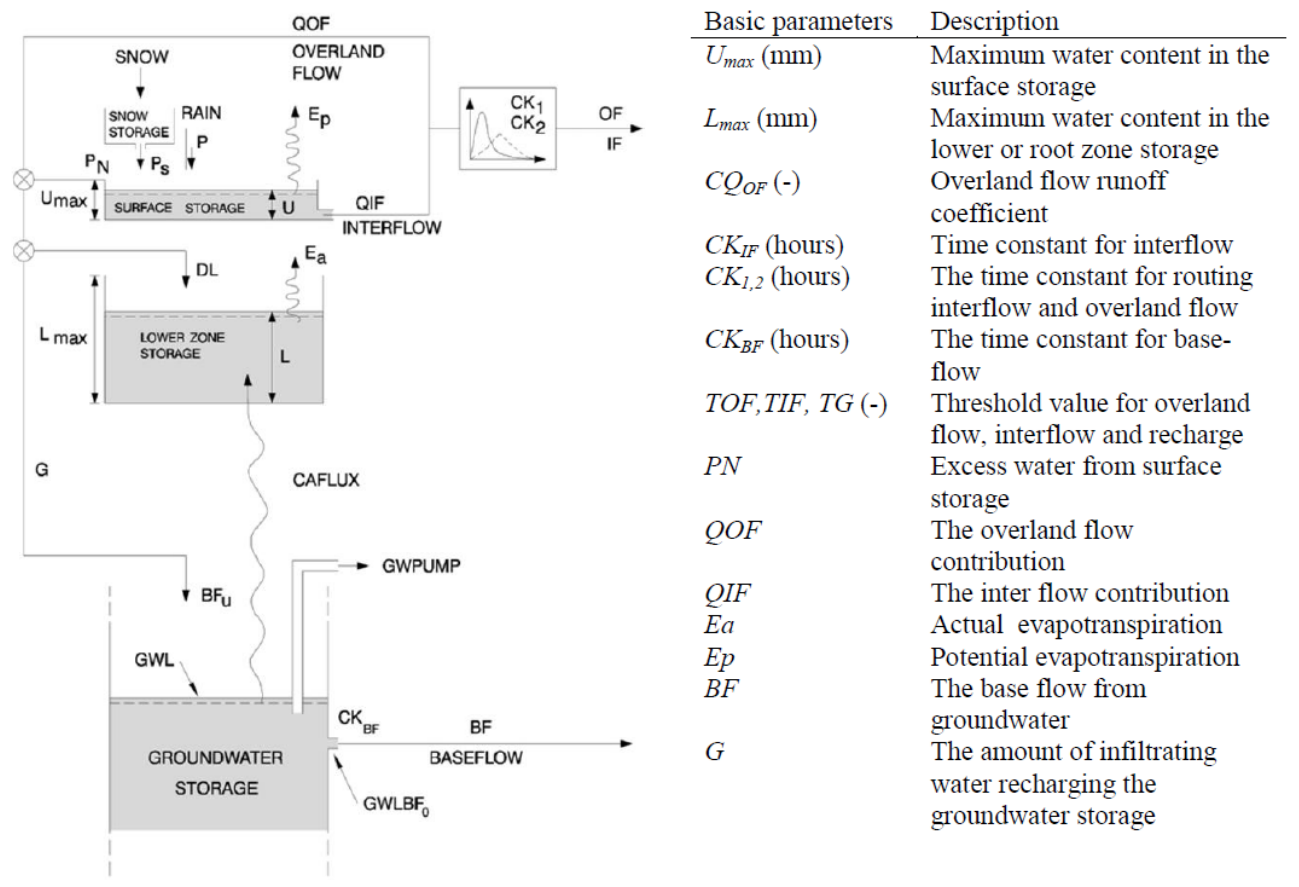

Fig. 3. Model structure of NAM and description of the basic parameters (DHI, 2008).

Table 1. VHM and NAM model performance in simulating the historical records for calibration and validation period.

\begin{tabular}{lrrrrr}
\hline \multirow{2}{*}{\begin{tabular}{l} 
Calibration \\
\cline { 2 - 3 } (Validation)
\end{tabular}} & \multicolumn{2}{c}{ Nyando } & & \multicolumn{2}{c}{ Lake Tana } \\
\cline { 2 - 3 } \cline { 5 - 6 } NSE & $0.4(0.3)$ & $0.46(0.4)$ & & $0.88(0.8)$ & $0.75(0.7)$ \\
WBD & $+7 \%(+20 \%)$ & $-7 \%(-14 \%)$ & & $-15 \%(-8 \%)$ & $-27 \%(5 \%)$ \\
\hline
\end{tabular}

Table 2a. Calibrated parameters of the VHM model for Nyando catchment.

\begin{tabular}{lrrrrr}
\hline \multicolumn{3}{c}{ Base-flow model } & \multicolumn{2}{c}{$\begin{array}{c}\text { Overland flow } \\
\text { model }\end{array}$} & \multicolumn{2}{c}{ Interflow model } \\
\hline$U_{\max }(\mathrm{mm})$ & 200 & $C_{1}(-)$ & -4.3 & $C_{1}(-)$ & -5 \\
$U_{\text {evap }}(\mathrm{mm})$ & 100 & $C_{2}(-)$ & 2 & $C_{2}(-)$ & 2.5 \\
$U_{\text {init }}(\mathrm{mm})$ & 100 & $C_{3}(-)$ & -2 & $C_{3}(-)$ & -0.5 \\
$C_{1}(-)$ & 1.9 & $C_{4}(-)$ & 1 & $C_{4}(-)$ & 0.2 \\
$C_{2}(-)$ & 0.2 & $\lambda(-)$ & 0.25 & $\lambda(-)$ & 0.25 \\
$C_{3}(-)$ & 3 & $r($ day $)$ & 1 & $r($ day $)$ & 1 \\
\hline
\end{tabular}

\subsubsection{Hydrological model performance evaluation}

For both VHM and NAM, the model performance was evaluated using Nash-Sutcliffe coefficient (NSE), water balance discrepancy (WBD) and graphical methods. WBD is calculated as the percentage difference between modelled and observed total flow (Eq. 5). The graphical methods were optimized by means of a multi-criteria model evaluation protocol included in the WETSPRO tool as described by Willems
Table 2b. Calibrated parameters of VHM model for Lake Tana catchment.

\begin{tabular}{lrlr}
\hline \multicolumn{2}{c}{ Base-flow model } & \multicolumn{2}{c}{ Quick flow model } \\
\hline$U_{\max }(\mathrm{mm})$ & 600 & $C_{1}(-)$ & -6 \\
$U_{\text {evap }}(\mathrm{mm})$ & 150 & $C_{2}(-)$ & 5.6 \\
$U_{\text {init }}(\mathrm{mm})$ & 150 & $C_{3}(-)$ & 1.7 \\
$C_{1}(-)$ & 1.94 & $C_{4}(-)$ & -1 \\
$C_{2}(-)$ & 0.24 & $\lambda(-)$ & 0.25 \\
$\mathrm{C}_{3}(-)$ & 2 & $r$ (day) & 1 \\
\hline
\end{tabular}

(2009). This model performance evaluation method includes a multi-objective set of goodness-of-fit statistics and complementary graphs.

$\mathrm{WBD}=\left(\frac{M-O}{O}\right) \cdot 100$

Where: $M$ is modelled total flow

$O$ is measured total flow 
Table 2c. Calibrated parameters of the NAM model for Nyando and Lake Tana catchments.

\begin{tabular}{lrrrrrrrrr}
\hline Parameters & $\begin{array}{r}U_{\max } \\
(\mathrm{mm})\end{array}$ & $\begin{array}{r}L_{\max } \\
(\mathrm{mm})\end{array}$ & $\begin{array}{r}\mathrm{CQOF}_{\mathrm{OF}} \\
(-)\end{array}$ & $\begin{array}{r}\mathrm{CK}_{\mathrm{IF}} \\
(\mathrm{h})\end{array}$ & $\begin{array}{r}\mathrm{CK}_{1,2} \\
(\mathrm{~h})\end{array}$ & $\begin{array}{r}\mathrm{TOF} \\
(-)\end{array}$ & $\begin{array}{r}\mathrm{TIF} \\
(-)\end{array}$ & $\begin{array}{r}\mathrm{TG} \\
(-)\end{array}$ & $\begin{array}{r}\mathrm{CK}_{\mathrm{BF}} \\
(\mathrm{h})\end{array}$ \\
\hline Nyando & 10 & 120 & 0.6 & 500 & 48 & 0.3 & 0.2 & 0.5 & 3000 \\
Lake Tana & 20 & 300 & 0.7 & 3000 & 888 & 0.3 & 0 & 0.7 & 1500 \\
\hline
\end{tabular}

Table 3. Mean annual values of rainfall, ETo and flow of Nyando catchment for the baseline (1971-1990) and scenario (2046-2065) period.

\begin{tabular}{lcccc}
\hline & $\begin{array}{c}\text { Precipitation } \\
\mathrm{mm}\end{array}$ & $\begin{array}{c}\text { Potential ET } \\
\mathrm{mm} \mathrm{day}^{-1}\end{array}$ & \multicolumn{2}{c}{$\begin{array}{c}\text { Discharge } \\
\mathrm{m}^{3} \mathrm{~s}^{-1}\end{array}$} \\
& & & VHM & NAM \\
\hline $\begin{array}{l}\text { Historical } \\
\text { Future }\end{array}$ & 1360 & 4.82 & \multicolumn{2}{c}{17.33} \\
\hline
\end{tabular}

Table 4. Factor change in daily peak/low flow extremes for Nyando catchment and specific return periods.

\begin{tabular}{rrr}
\hline $\begin{array}{r}\text { Return period } \\
\text { (years) }\end{array}$ & \multicolumn{2}{c}{$\begin{array}{c}\text { Range of change } \\
\text { (change factor) } \\
\end{array}$} \\
Peak flows & Low flows \\
\hline 1 & $1.0-2.4$ & $0.7-1.8$ \\
2 & $1.1-2.4$ & $0.8-1.4$ \\
5 & $1.1-2.6$ & $0.5-1.5$ \\
10 & $1.2-3.8$ & $0.9-1.8$ \\
\hline
\end{tabular}

\subsection{Developing climate scenarios}

Developing climate change scenarios was performed using an ensemble of GCM simulations driven by two GHG emission scenarios, A1B and B1 of the SRES scenarios of IPCC (2001). Prior to developing the future scenarios consistency check was performed between the GCM control simulations and observed meteorological data to assess each model's representativeness for the two catchments. The station data were compared with the GCM results for the grid cell covering the station. To account for the difference between point data and grid averaged data, areal reduction factors (Fiddes et al., 1974) were applied to the station data. After applying these factors to the series, it was observed that while some of the GCMs showed decreased biases, other GCMs showed increased biases. This observation was consistent across the different scales: daily, monthly, seasonal and annual aggregations. However, for this study the models were mainly assessed at the monthly, seasonal and annual scales where the areal reduction factor can be taken as close to one. The different GCM runs were tested for their capacity to reproduce the reference (observed) climate (rainfall, maximum and minimum temperature) based on RMSE, bias, and frequency analysis (Baguis et al., 2010; Nyeko-Ogiramoi et al., 2010). GCM runs found to consistently perform poorly in the different tests were excluded from the subsequent analysis.

\subsubsection{GCM model performance evaluation}

This statistical analysis was performed for different aggregation levels: monthly, seasonal and annual. Mean values were computed for temperature while total accumulated values were computed for rainfall. RMSE and bias were computed using Eqs. (6) and (7), respectively. The results were presented as percentage RMSE/bias, which was calculated as the ratio of RMSE/bias to the mean of the target variable.

$E=\sqrt{\frac{1}{K} \sum(X-Y)^{2}}$

$B=\frac{1}{K} \sum(X-Y)$

where: $X$ is the time series of the control simulation, and $Y$ is the corresponding time series of observations of the same physical quantity (temperature and/or rainfall); $K=12$ for the monthly aggregation level or equal to the number of years for the seasonal or annual aggregation level.

In addition, frequency/quantile analysis was performed to assess the model's ability to predict extreme events at seasonal and annual aggregation levels. This analysis is based on ranked values of both control and observed time series, where the corresponding values are compared for the same empirical return period. The empirical return period for each quantile in the ranked series was calculated from Eq. (8). Evaluation of the results was aided by frequency distribution plots. This enabled to identify outliers that were greatly different from the observed extreme events.

$T=\frac{n}{r}$ 
Table 5. Mean annual values of rainfall, ETo and flow of Lake Tana catchment for the control (1991-2000) and future (2046-2065) period.

\begin{tabular}{lccc}
\hline & $\begin{array}{c}\text { Precipitation } \\
\mathrm{mm}\end{array}$ & $\begin{array}{c}\text { Potential ET } \\
\mathrm{mm} \mathrm{day}^{-1}\end{array}$ & \multicolumn{2}{c}{$\begin{array}{c}\text { Discharge } \\
\mathrm{m}^{3} \mathrm{~s}^{-1}\end{array}$} \\
& & $\mathrm{VHM}$ & $\mathrm{NAM}$ \\
\hline $\begin{array}{l}\text { Control period } \\
\text { Future period }\end{array}$ & 1374 & 4.38 & \multicolumn{2}{c}{141.05} \\
\hline
\end{tabular}
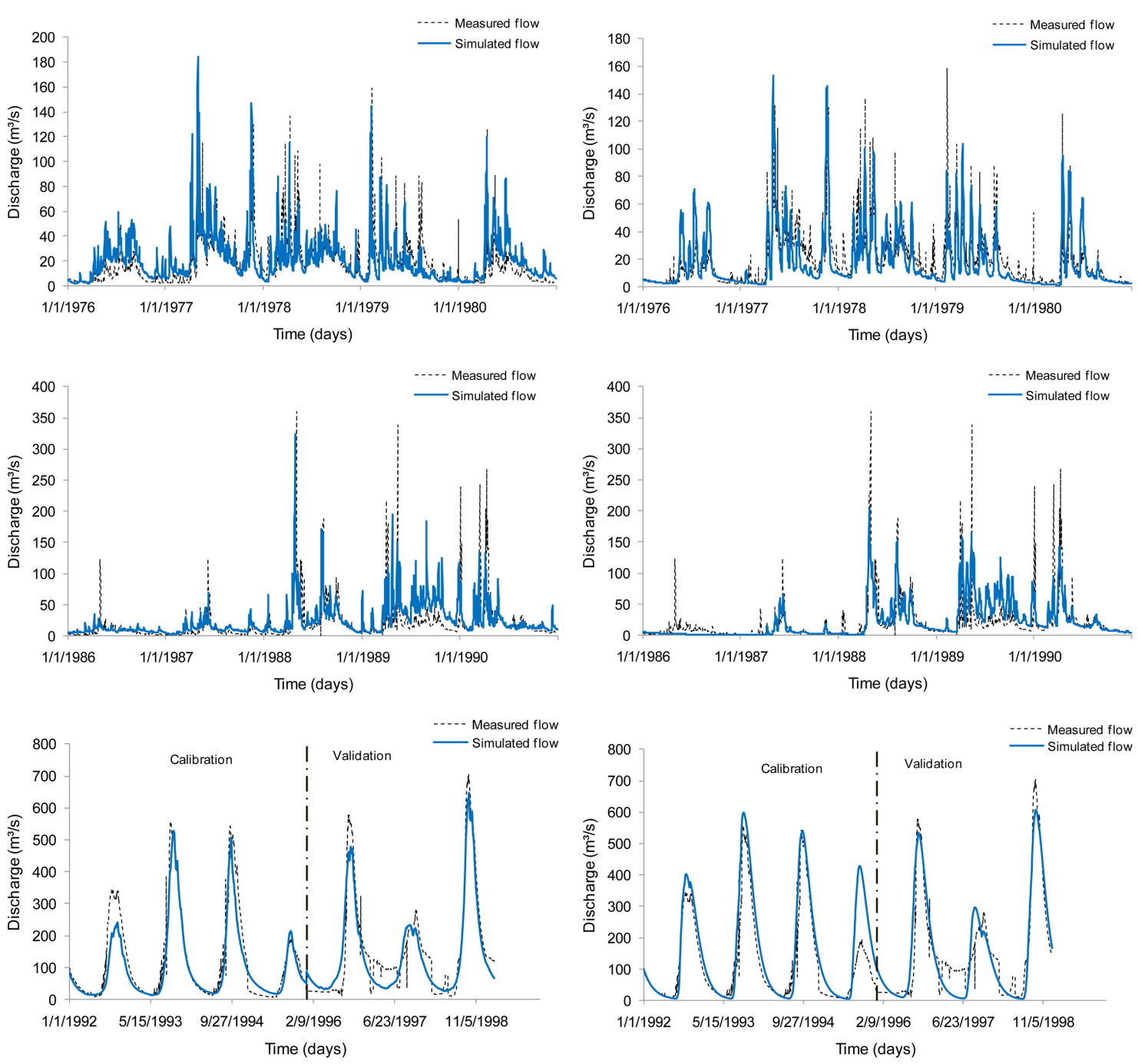

Fig. 4. Calibration and validation time series plots using VHM (left) and NAM (right) models for Nyando and Lake Tana catchment. Calibration of Nyando (top), validation of Nyando (middle) and both calibration/validation of Lake Tana (bottom).

where: $T$ is the empirical return period, $n$ is the total number of years the data is taken from, $r$ is the rank number

\subsubsection{Projected changes}

Expected climate changes in rainfall, temperature and ETo were determined as the ratio of the value in the scenario period to the value of the control period, known as perturbation factor. In case of rainfall, an approach based on frequency analysis of quantiles was applied where perturbation factors were obtained by comparing quantiles for given empirical return periods (or values of the same rank) in both the control and scenario series (Chiew, 2006; Harrold et al., 2005; Olsson et al., 2009). This perturbation calculation was done using only wet days where a wet day was defined as a day receiving a minimum rainfall amount of $0.1 \mathrm{~mm}$. The value $0.1 \mathrm{~mm}$ was chosen as a standard wet-day threshold based on previous studies such as in Elshamy et al. (2009a). 

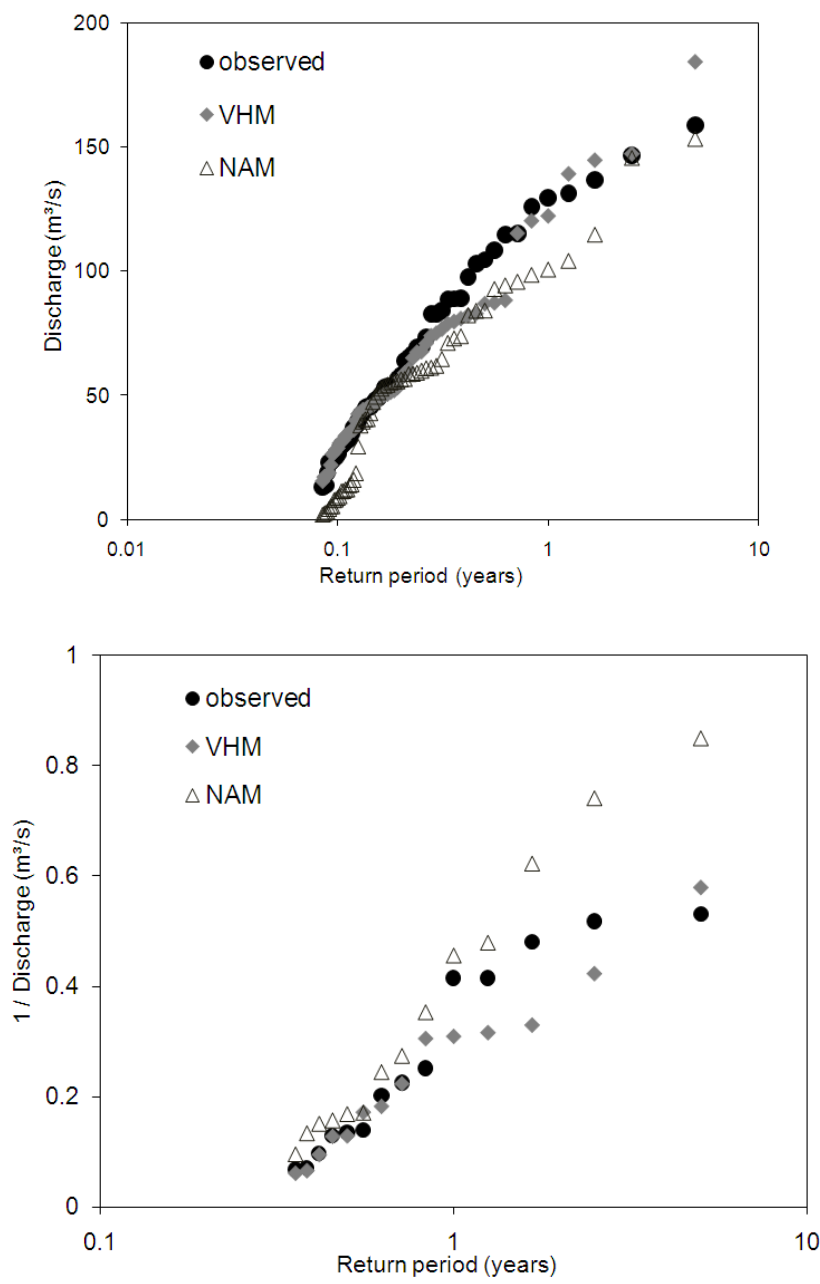

Fig. 5. Return period of daily peak flow extremes (top) and low flow extremes (bottom) for Nyando catchment: comparison of observations with model results during calibration period (1976-1980).

The procedure to calculate the change in daily rainfall time series is as follows:

- Two time series were selected, the control period and the future scenario period.

- Both time series were ranked independently giving rank 1 to the highest value, rank 2 to the second highest and so forth.

- The ratio between scenario and control was calculated as Eq. (9) giving a unit-less value.

$P F_{i}=\frac{P r_{s}}{P r_{c}}$

where: $P F$ is the perturbation factor, $i$ is the rank number, $\mathrm{Pr}$ is the rainfall, $s$ and $c$ are subscripts depicting scenario and control series respectively.
Next to the quantile perturbation calculation for the wet day rainfall intensities, changes in the wet day frequencies were calculated. The day to day variability was addressed through the adjustment of the length of wet and dry spells. Among different possible methods, this study used a random approach that keeps altering the wet and dry spells. The percentage change in mean wet spell length is calculated from the wet spells (longer than 2 days) in the control and scenario GCM runs. A percentage increase in wet spell length is implemented through adding wet days to the beginning or end of the wet spells in the observed series. The added intensity is randomly generated from the existing days in the wet spell. The wet spell adjustment begins with the longest wet spells and proceeds to the shorter wet spells until the added wet days are adequate. The wet days are considered adequate when the total change in monthly volume is close to (within 10\%) the percentage change projected from the climate models.

The quantile perturbation approach is particularly appropriate for the climate change impact on extremes as it makes use of quantile perturbation factors; that is change factors dependent on the return period. This overcomes the limitation of using mean changes on all quantiles which may underestimate changes in extremes. The observed rainfall series are perturbed first by removing or adding wet days in the series using the random approach described earlier and secondly by applying intensity perturbation to each wet day dependent on the empirical return period (thus rank) of the rainfall intensity. However, for ETo the classical change factor method was employed (Diaz-Nieto and Wilby, 2005; Prudhomme et al., 2002). The observed ETo series were perturbed by multiplying with a monthly varying factor; that is all values within a specific month multiplied by one factor.

\subsection{Impact analysis}

After future scenarios were constructed for rainfall and ETo, the original and perturbed series were then used to drive the hydrological models for the two catchments in order to assess the influence of climate change. The hydrological models were run using observed and future scenarios followed by statistical post processing of the hydrological simulation results. Changes in cumulative volume of flow in time (annual, seasonal and monthly), high and low flow extremes together with analysis of rainfall and evapotranspiration were estimated.

The extraction of the high flow peaks and the low flow minima from the time series based on the method by Willems (2009) was adopted where the peak over threshold (POT) selection was performed using three "independency" criteria. For low flows, the method of POT selection was applied after 1/Q transformation of the discharge series, where $\mathrm{Q}$ refers to the original discharge time series. This transformation changes the flow minima to maxima, which facilitates 

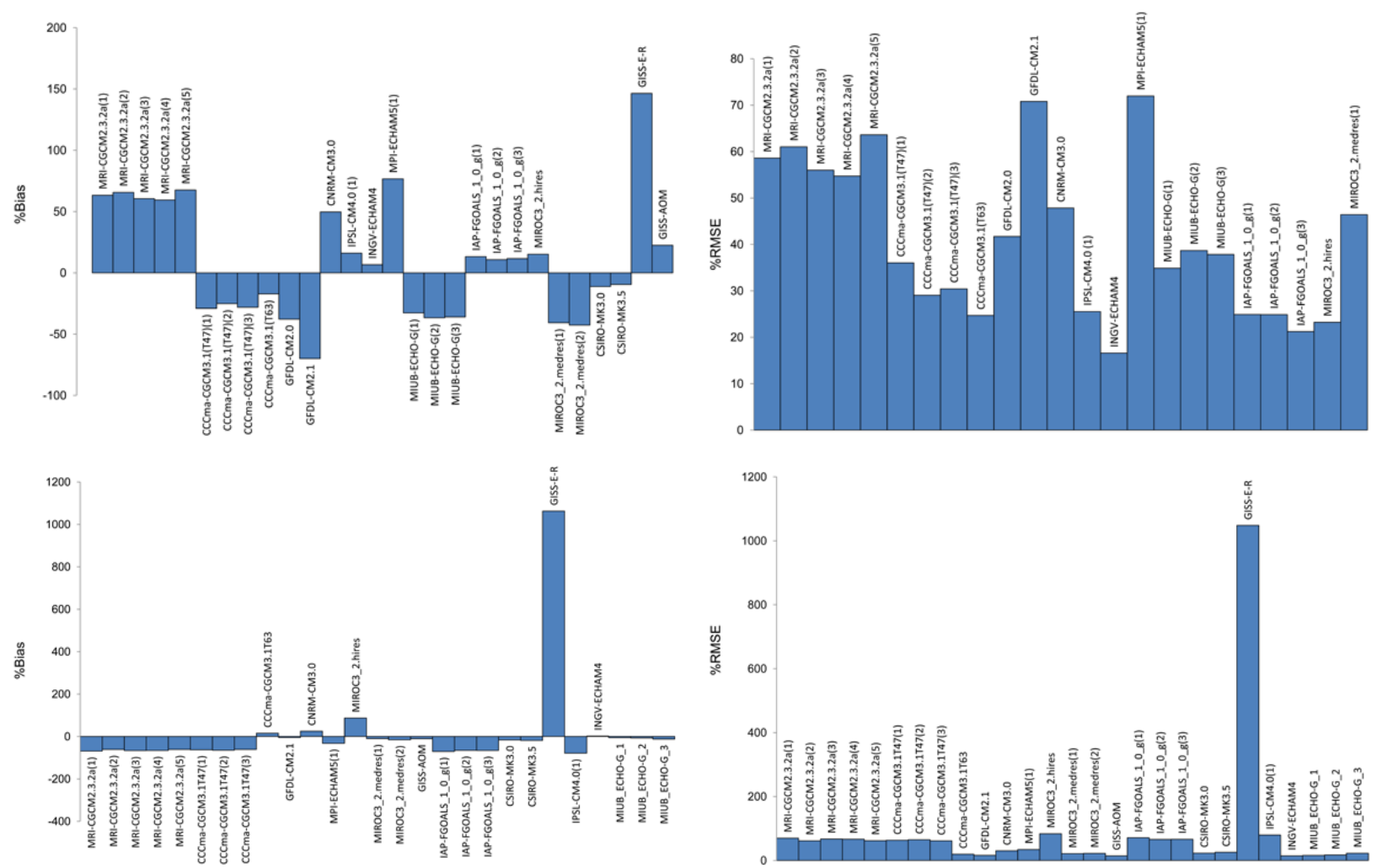

Fig. 6. Bias (left) and RMSE (right) of GCM based annual rainfall versus observations at Kisumu (top) and Bahir dar (bottom).

the extraction of "nearly independent" low flows. After the selection, the 1/Q series is transformed back to the original flows to determine their percentage change.

The cumulative volume results from the two hydrological models were compared for both the current and the future climate conditions. This helped to check the sensitivity of the results to the modelling technique selected. The regional difference between the two selected catchments was compared on their response to the climate change scenarios.

\section{Results and discussion}

\subsection{Hydrological models performance}

The performance of both VHM and NAM models is summarized in Table 1. The findings show that in terms of NSE and WBD the capacity of reproducing the historical time series by the models is similar for a given catchment. However, the models performed better for Lake Tana catchment than for Nyando catchment. This partly could be explained by the characteristics of the catchments. Lake Tana catchment has a special feature which is the lake that attenuates the peak flows and the flow series is much smoother than in the Nyando case. Time series graphs are included in Fig. 4 for both catchments and Table 2 includes calibrated parameters of the two models for both catchments. The models were also evaluated for their ability to predict more extreme conditions for both peak and low flows. The performance of the models in simulating extremes for Nyando catchment is shown in Fig. 5. The graphs show that the VHM model has better simulation capacity than the NAM model in terms of extreme flows. This is proved by the historical observations' probability distribution which is closer to the VHM model results than the NAM results. The model structure identification and calibration method of VHM model contributed to its better performance in extreme flows than NAM model. Thus, VHM model results were given higher credibility when analyzing the impact assessment of climate change on the extremes. In the following sections VHM model results will be presented and discussed for impact of climate change on extremes.

\subsection{GCMs performance}

In total, results of 28 runs with 17 GCMs and two GHG emission scenarios (A1B and B1) have been obtained from the IPCC AR4 Archive for the grid cells covering the study areas. For each of these runs, RMSE and bias evaluations were performed for both rainfall and temperature at annual, seasonal and monthly aggregation levels. The performance is based on the grid cell covering the selected stations described in Sect. 2.1. Figure 6 presents the results obtained 

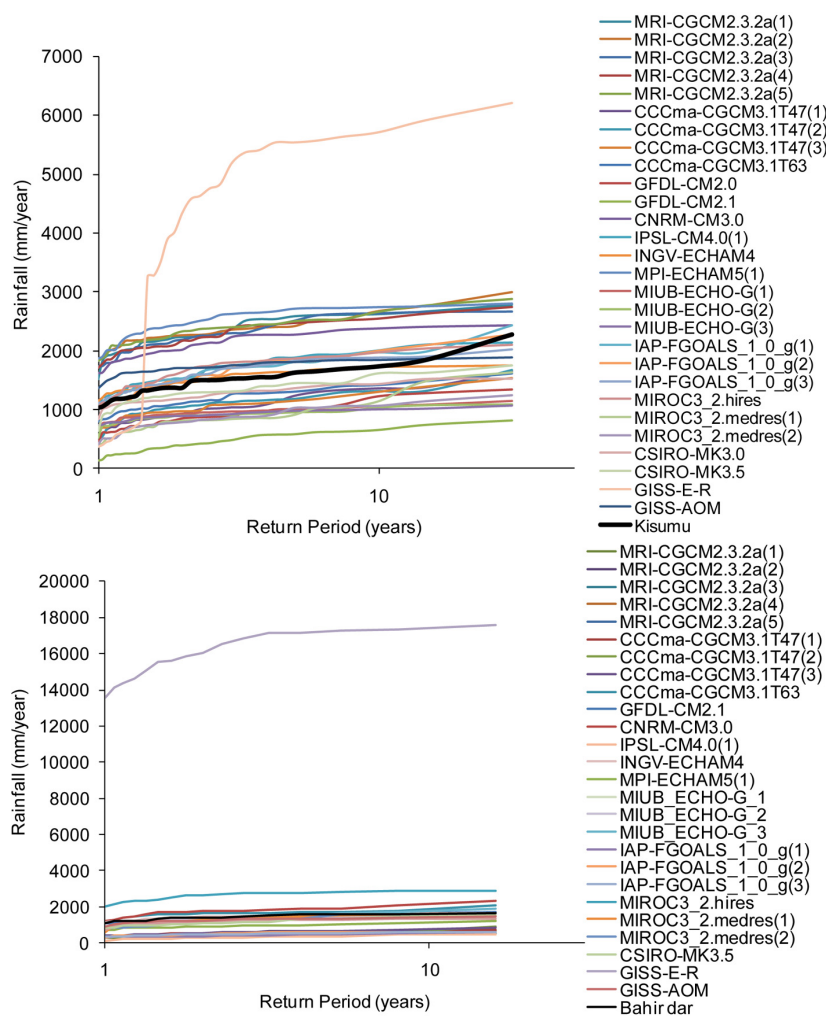

Fig. 7. Return period of annual rainfall quantiles: comparison of GCM results over Nyando (top) and Lake Tana (bottom) catchments with observations at Kisumu and Bahir dar, for control period (1971-1990) and (1991-2000) respectively.

for the annual rainfall analysis in both catchments. The projections show both under- and overestimation for the 2050s. In addition, the quantile/frequency analysis, which was used to assess the ability of the models to simulate extreme rainfall events, produced results as in Fig. 7. Models that perform poorly could be identified from such analysis. For example, GISS-E-R model shows anomalous behaviour in both catchments. Such models were excluded from the impact analysis. Similar analysis was conducted to evaluate the performance of the GCM simulations for temperature. Figure 8 shows the seasonal analysis of bias for daily maximum temperature in boreal winter (DJF) and boreal summer (JJA).

These different statistical tests on GCMs performance to simulate historical records of climatic variables show generally better simulation results for temperature than rainfall. This result is expected as rainfall is naturally more variable and more controlled by local conditions. The poor simulation result of GCMs for rainfall is also due to their failure to simulate the seasonal migration of the ITCZ in these equatorial regions (Wu et al., 2003).

Generally, the historical rainfall is better simulated by the GCMs for Nyando catchment than for Lake Tana catchment. The poor simulation for Lake Tana catchment is attributed to both the topography and the complex climate system. Given the coarse resolution of GCMs the change in topography is most probably not adequately modelled. On the other hand, the summer (JJA) rainfall in the catchment is influenced by monsoon activity (Beyene et al., 2010), which might not be accurately considered by the GCMs.

No particular GCM run performed consistently well at all timescales, either for all tests or for both variables and catchments. Therefore, the performance of a GCM run is basin specific. However, there is better convergence among the GCM runs in the Nyando catchment (Lake Victoria area) than in the Lake Tana catchment (Blue Nile area), similarly to what was found by Hulme et al. (2001) and IPCC (2001).

\subsection{Nyando catchment response}

The period 1971-1990, was used as baseline period with 2046-2065 representing the future scenarios for the 2050s. Table 3 shows the mean values of rainfall, ETo and flow for both baseline and scenario periods. The impact on annual mean flow by 2050s gave a wide range of results as shown in Table 3. The mean annual rainfall change is in the range $-10 \%$ to $31 \%$, while change in evapotranspiration ranges from $-6 \%$ to $9 \%$. For these projected rainfall and ETo changes the projected mean annual flow change is between $-27 \%$ and $118 \%$ using VHM simulations while the range is from $-34 \%$ to $149 \%$ using NAM. This range of change reveals some insights in the influence the hydrological model structure on the future impact. First, the NAM model range is wider than the VHM implying that it projects the driest and wettest futures. However, the difference is more pronounced for the wettest scenario. This could be explained from the model calibration which showed that the NAM model performs less well for extremes (Fig. 5). This means that the range of future impacts is associated with the performance of the model for the current climate. Additionally, wider variations are observed between the rainfall projections than between the evapotranspiration projections. Consequently, the large impact range on the river flow is explained mainly by the considerable uncertainty in the rainfall projections. Similar to the annual mean flow change, the seasonal analysis showed wide and varied magnitude of change for the different seasons. However, most of the GCMs agree in projecting increase in the river flow across all seasons.

Next to impact analysis on cumulative volumes, the impact on extreme flows was analyzed. Here the impact analysis used results from VHM model as it had better performance than NAM model in the hydrological model performance analysis. Thus according to VHM outputs, peak flows of Nyando River until the 2050s generally tend to increase (Fig. 9). Nevertheless, the projected changes in low flows show both increases and decreases of the flow values from the control period (Fig. 9). For application purposes specific return periods were selected to look at the range of change. Table 4 shows this range of changes from the different GCM 

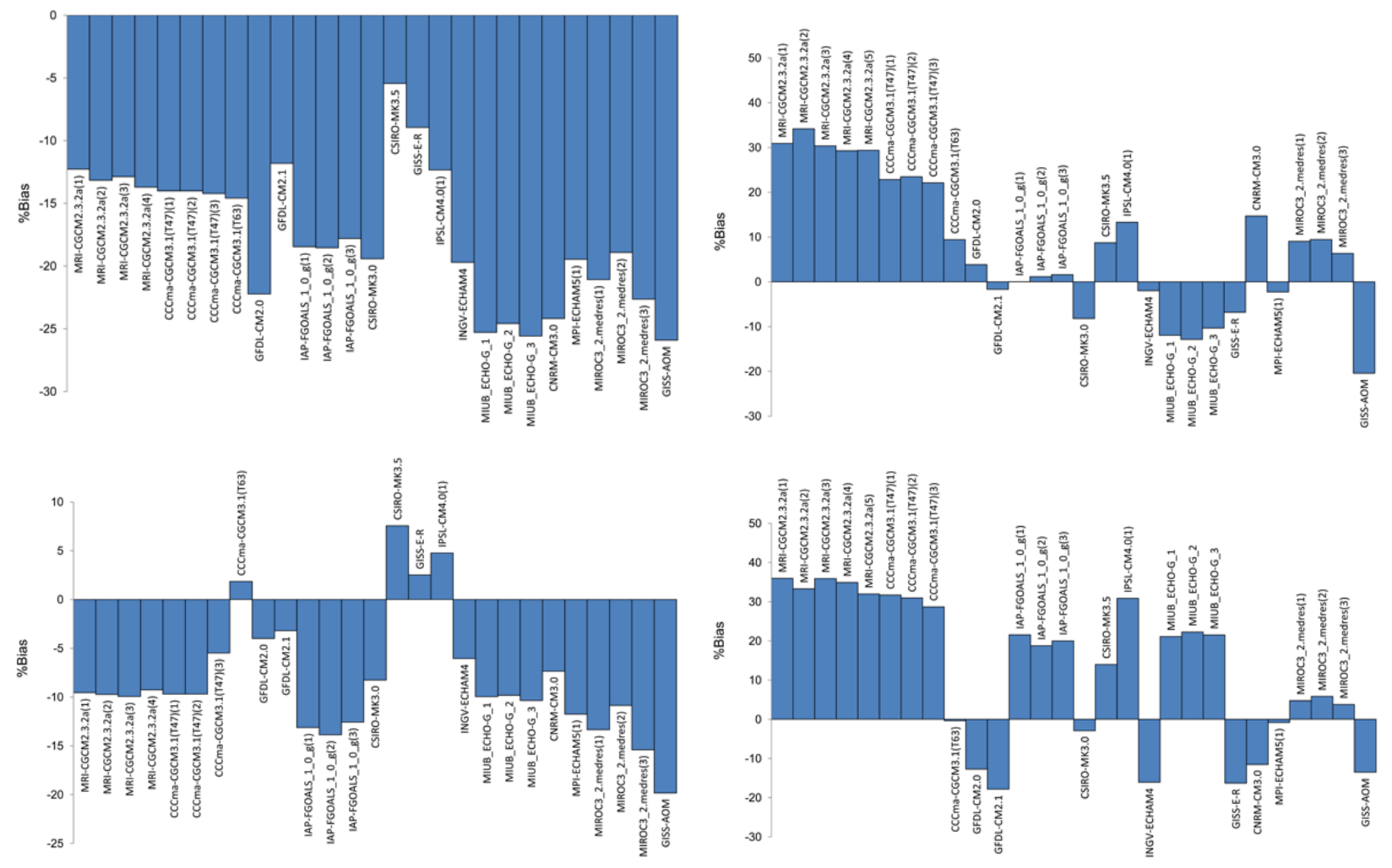

Fig. 8. Bias of daily maximum temperature for winter (top) and summer (bottom) seasons at Kisumu (left) and Bahirdar (right).

runs as a function of return period. The GCMs agree in projecting increase for the peak flows even though the magnitudes are different. These projected increases in the peak flows indicate the possibility of increased number and extent of flooding events in the catchment. This is of major concern as this area has records of damage due to severe flooding experience in the past.

\subsection{Lake Tana catchment response}

In case of the Lake Tana catchment the period 1990-2000 (11years of data) was used as baseline period to run the hydrological models. Table 5 shows the mean values of rainfall, ETo and flow for both baseline and scenario periods. Comparing the baseline period with the 2050s future scenarios, the mean annual flow change ranges from $-72 \%$ to $75 \%$ using VHM and $-81 \%$ to $68 \%$ using NAM model. Compared to the Nyando catchment, the range of VHM and NAM impacts is somewhat similar. It is useful to recall that the hydrological performance for the Lake Tana catchment was also better than the Nyando catchment (Table 1). Hence, the differences in the hydrological models are not reflected in the impact. Therefore, the future change in impact is mainly explained by the GCM uncertainty. The wide impact in the flow is explained by considerable change in climate variables, mainly precipitation. The precipitation projections cover a broader range than the evapotranspiration projections; simi- lar to what has been found for Nyando. The range of change in precipitation and ETo are from $-30 \%$ to $18 \%$ and from $1 \%$ to $8 \%$ respectively. In annual, seasonal and monthly scale, approximately half of the GCM runs project increased flow and the other half project decreases. It is therefore highly uncertain whether the future will have increased or decreased flows for the 2050s.

Similar to the mean volume analysis the projected extreme flow results show a wide range. Figure 10 is presented as an illustration on how the GCMs project peak flows in the Lake Tana catchment. This creates uncertainty on whether to expect higher or lower peak and low flows for the 2050s. To summarize the range of possible projections in terms of highest, mean and lowest impacts; the maximum, mean and minimum are calculated. For each return period the percentage change is calculated after which the average for all the return periods is computed. The average percentage change of peak flows for the highest, mean and lowest scenarios are $+79 \%,+10 \%$ and $-31 \%$, respectively. Similar analysis for the low flows gave $+56 \%,+12 \%$ and $-61 \%$ for highest, mean and lowest scenarios respectively.

\subsection{Regional difference}

Though the period used for the two catchments and the number of GCM runs considered was not the same, the regional comparison provided useful information regarding the 


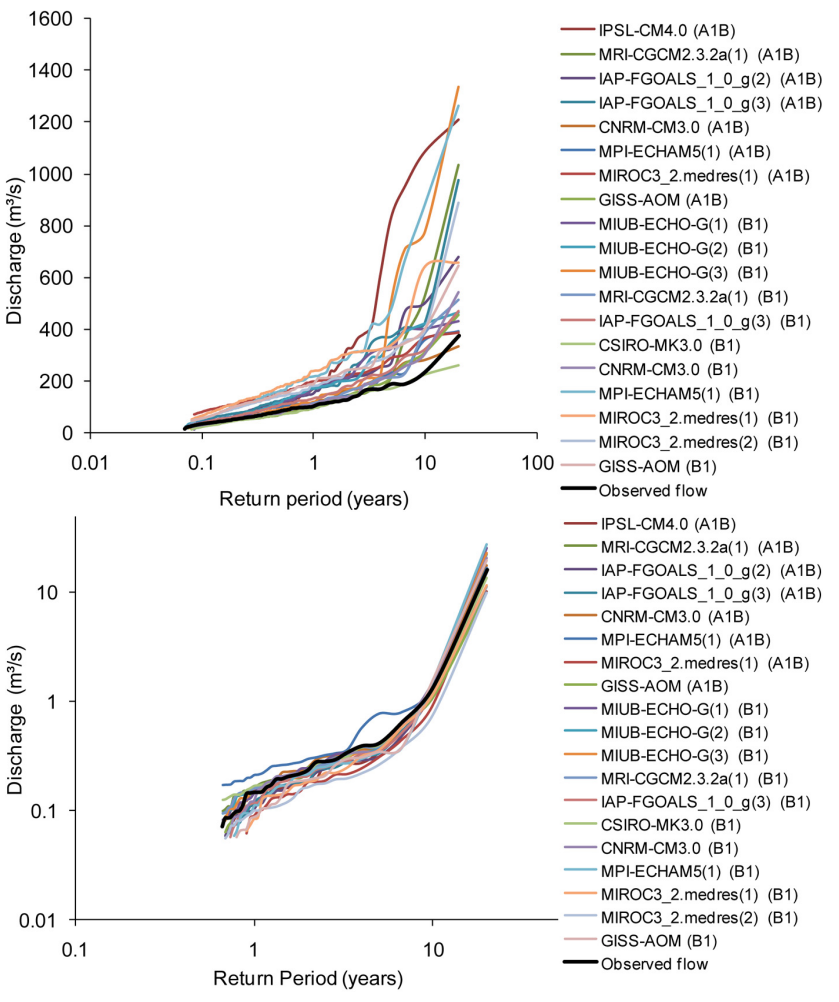

Fig. 9. Return period of daily peak flow extremes (top) and low flow extremes (bottom) for Nyando catchment, for control period (19711990) and future period (2046-2065) based on different GCM runs (VHM) results.

potential differences in the future impacts for the same time horizon (2050s) and similar GCMs. A general overview was made using the GCM runs that were common for both catchments. The projected change in annual mean flow using four GCMs for both catchments is as shown in Fig. 11. This result illustrates that for the 2050s the flow in Nyando catchment will likely increase more than for the outflow of Lake Tana catchment. This higher increase is perhaps explained by both the hydrological model uncertainty and the GCM uncertainty. While the GCM models performed better for the Nyando catchment, the GCMs perform less well for Lake Tana catchment. Conversely, the hydrological models performed less well for the Nyando catchment than Lake Tana catchment. Therefore for Nyando, the wider range of impact is partly explained by the performance of the hydrological model. The impact differences between A1B and B1 emission scenarios are also shown in Fig. 11. It is not clear, for the Nyando catchment, which emission scenario leads to a higher wet extreme impact. For example, the A1B scenario runs by the CM4.1 and MIROC3 models show opposite impacts than those by the B1 scenario run. For Lake Tana catchment, the differences in the extreme wet scenario for the $\mathrm{A} 1 \mathrm{~B}$ and $\mathrm{B} 1$ scenarios are marginal compared to the Nyando catchment but the A1B scenario projects a wetter

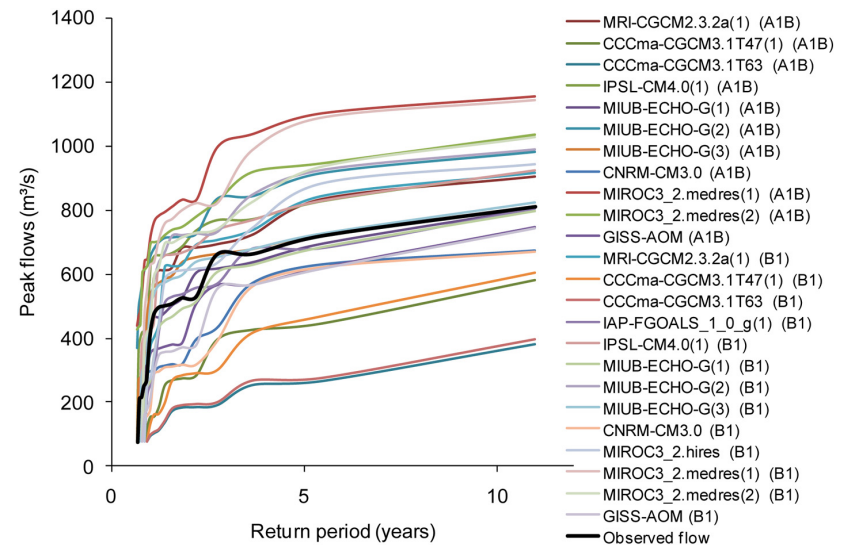

Fig. 10. Return period of daily peak flow extremes for Lake Tana catchment, for future period (2046-2065) (VHM results).

climate. Therefore, for Lake Tana catchment the influence of emission scenarios on the future impact is not as pronounced compared to the Nyando case.

Generally, the climate change impact for the two catchments revealed two different situations. The Nyando River showed increasing flow trends until the 2050s for mean flows at higher temporal scale and also for extreme peak flows; while the Lake Tana catchment showed unclear trends. The Nyando results are comparable to a study conducted by Githui et al. (2009) on the Nzoia River in Kenya. In that study, mean annual rainfall values were found to change between $2.4 \%$ and $23.2 \%$, corresponding to stream flow changes in the range from $6 \%$ to $115 \%$. The research, however, used limited number of GCM runs and was based on monthly data. For water management decision purposes, the increasing flow trends observed for the Nyando catchment are major concerns. This catchment is already prone to major flood related socio-economic problems.

\section{Conclusions}

This study aimed at achieving two goals: studying the climate change impacts on Nyando and Lake Tana catchments, which are two representative source regions for the White and Blue Nile basins respectively, and investigating hydrological impact uncertainties. It made use of evaluated GCM runs (17 GCMs in total, for A1B and B1 GHG emission scenarios) to develop and construct an ensemble set of climate change scenarios for hydrological impact assessment. The impact assessment was performed based on NAM and VHM lumped conceptual hydrological models.

The GCMs showed wide range of ability in simulating rainfall, maximum and minimum temperature. In addition, clear variation was observed on the obtained climate change signal according to the GCM and emission scenario considered. Wider signals were observed for rainfall than for 


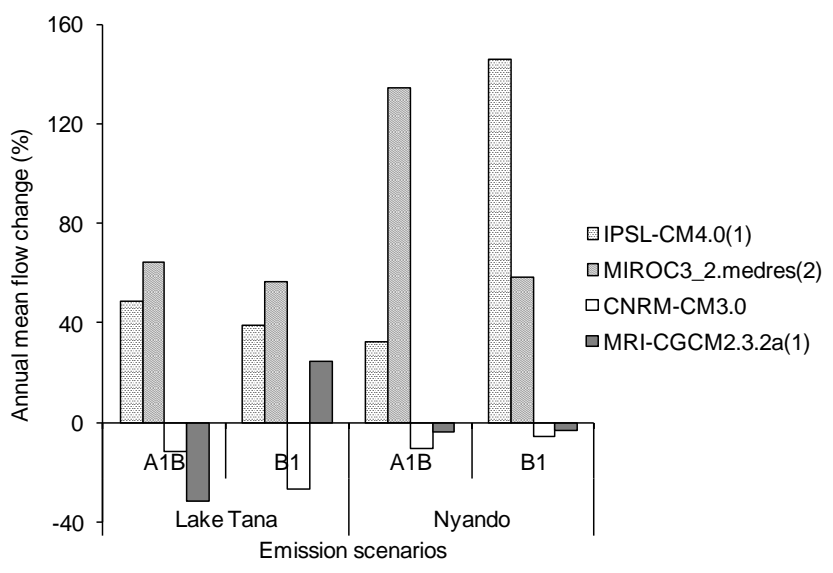

Fig. 11. Regional projected change comparison of mean annual flow volumes between Nyando and Lake Tana catchments for eight GCM runs (VHM results).

the temperature. This showed that climate change impact assessment based on only few climate models and emission scenarios would not be prudent. It would largely underestimate the climate change uncertainty. Instead, an ensemble approach as applied in this study is advisable to fully capture the uncertainty.

This study showed the performance of the two hydrological models in simulating the historical flows was similar when looking at each catchment separately. But the hydrological model performance was better for Lake Tana catchment. It was found that the performance of the hydrological model also influenced the future impacts especially for the most extreme wet scenario. This finding underscores the need of more than one hydrological model to evaluate the credibility of the hydrological model for future impact investigations on hydrological extremes.

The findings from Lake Tana catchment illustrate that the uncertainty observed in the impact analysis of mean and extreme flows was mainly attributed to the GCMs uncertainty. The performance of the hydrological models for the historical records was indeed good, but the projected impact results were highly uncertain.

Overall, the range of projections obtained in this research is much wider than in previous studies. This is due to the wider range of GCM runs used and the hydrological models. The uncertainties related to the precipitation projection of GCMs suggest the necessity of improvements. In addition, the use of Regional Climate Models (RCMs) would be better for hydrological impact studies as their spatial resolution is less coarse than the GCMs. RCMs would indeed enable better coverage of topographical variations across the catchments such as the Lake Tana catchment.

Acknowledgements. The research was carried out using data from the FRIEND/NILE projects of UNESCO and Flemish Government of Belgium, the Ministry of Water Resources and the National Meteorological Services Agency in Ethiopia. The authors acknowledge these institutes for the provision of data.

Edited by: H. Cloke

\section{References}

Allen, R. G., Pereira, L. S., Raes, D., and Smith, M.: Crop evapotranspiration - guidelines for computing crop water requirements - FAO Irrigation and drainage paper 56, FAO - Food and Agriculture Organization of the United Nations, Rome, 1998.

Andersson, L. Wilk, J., Todd, M., Hughes, D., Earle, A., Kniveton, D., Layberry, R., and Savenije, H.: Impact of climate change and development scenarios on flow patterns in the Okavango River, J. Hydrol., 331, 43-57, 2006.

Baguis, P., Roulin, E., Willems, P., and Ntegeka, V.: Climate change scenarios for precipitation and potential evapotranspiration over central Belgium, Theor. Appl. Climatol., 99, 273-286, 2010.

Beyene, T., Lettenmaier, D. P., and Kabat, P.: Hydrologic impacts of climate change on the Nile River basin: Implications of the 2007 IPCC scenarios, Climatic Change., 100, 433- 461, 2010.

Booij, M. J.: Extreme daily precipitation in Western Europe with climate change at appropriate spatial scales, Int. J Climatol., 22, 69-85, 2002.

Booij, M. J.: Impact of climate change on river flooding assessed with different spatial model resolutions, J. Hydrol., 303, 176198, 2005.

Chiew, F. H. S.: An Overview of Methods for Estimating Climate Change Impact on Runoff. In: 30th Hydrology and Water Resources Symposium, Lauceston, Australia, pp. CDROM (ISBN 0-8582579-0-4), 2006.

Conway, D.: From headwater tributaries to international river: observing and adapting to climate variability and change in the Nile Basin, Global Environmental Change., 15, 99-114, 2005.

Conway, D. and Hulme, M.: Recent fluctuations in precipitation and runoff over the Nile subbasins and their impact on main Nile discharge, Climatic Change, 25, 127-151, 1993.

Conway, D. and Hulme, M.: The impacts of climate variability and future climate change in the Nile basin on water resources in Egypt, Water Resour. Development., 12, 277-296, 1996.

Delworth, T. L. and Mann, M. E.: Observed and simulated multidecadal variability in the Northern Hemisphere, Climate Dyn., 16, 661-676, 2000.

DHI: MIKE11 - Reference and User's Manual, DHI Water and Environment, Hørsholm, Denmark, 2008.

Diaz-Nieto, J. and Wilby, R. L.: A comparison of statistical downscaling and climate change factor methods: impacts on low flows in the River Thames, United Kingdom, Climatic Change, 69, 245-268, 2005.

Elshamy, M. E. and Wheater, H. S.: Performance assessment of a GCM land surface scheme using a fine-scale calibrated hydrological model: an evaluation of MOSES for the Nile Basin, Hydrol. Process., 23, 1548-1564, doi:10.1002/hyp.7298, 2009.

Elshamy, M. E., Seierstad, I. A., and Sorteberg, A.: Impacts of climate change on Blue Nile flows using bias-corrected GCM scenarios, Hydrol. Earth Syst. Sci., 13, 551-565, doi:10.5194/hess13-551-2009, 2009a. 
Elshamy, M. E., Sayed, M. A. A., and Badawy, B.: Impacts of climate change on Nile flows at Dongola using statistically downscaled GCM scenarios, Nile Water Science and Engineering Magazine 2, Special issue on Water and Climate, 1-14, 2009b.

Fiddes, D., Forsgate, J.A., and Grigg, A.O.: The prediction of storm rainfall in East Africa. Transport and Road Research Laboratory report 623, Environment Division Transport Systems Department, Transport and Road Research Laboratory, Crowthorne, Berkshire, 1974.

Githui, F., Gitau, W., Mutua, F., and Bauwens, W.: Climate change impact on SWAT simulated streamflow in western Kenya, Int. J. Climatol., 29, 1823-1834, 2009.

Harrold, T. I., Chiew, F. H. S., and Siriwardena, L.: A method for estimating climate change impacts on mean and extreme rainfall and runoff, in: 16th International Congress on Modelling and Simulation, Melbourne, Australia, 497-504, 2005.

Hulme, M., Doherty, R., Ngara, T., New, M., and Lister, D.: African climate change: 1900-2100, Climate Res., 17, 145-168, 2001.

IPCC: Climate Change 2001, in: The Scientific Basis, Contribution of Working Group I to the Third Assessment Report of the Intergovernmental Panel on Climate Change (IPCC), edited by: Houghton, J. T., Ding, Y., Griggs, D. J., Noguer, M., van der Linden, P. J., and Xiaosu, D., Cambridge University Press, UK, 944 pp., 2001.

IPCC: Climate Change 2007, in: Impacts, Adaptation and Vulnerability, Contribution of Working Group II to the Fourth Assessment Report of the Intergovernmental Panel on Climate Change (IPCC), edited by: Parry, M. L., Canziani, O. F., Palutikof, J. P., van der Linden, P. J., and Hanson, C. E., Cambridge University Press, Cambridge, UK, 1000 pp., 2007.

Jiang, T., Chen, T. D., Xu, C. Y., Chen, X., Chen, Xi, and Singh, V. P.: Comparison of hydrological impacts of climate change simulated by six hydrological models in the Dongjiang Basin, South China, J. Hydrol., 336, 316-333, 2007.

Kim, U., Kaluarachchi, J. J., and Smakhtin, V. U.: Climate change impacts on hydrology and water resources of the Upper Blue Nile River Basin, Ethiopia, International Water Management Institute Research Report., 126, 27 pp., 2008.

Muthusi, F. M., Gathenya, M., Gadain, H., Kaluli, W., and Lenga F. K.: Application of the Usgs Streamflow Model to the Nyando Basin, Western Kenya, European Journal of Scientific Research., 12, 9-19, 2005.

Nyeko-Ogiramoi, P., Ngirane-Katashaya, G., Willems, P., and Ntegeka, V.: Evaluation and inter-comparison of Global Climate Models' performance over Katonga and Ruizi catchments in Lake Victoria basin, Phy. Chem. Earth, 35, 618-633, 2010.
Olsson, J., Berggren, K., Olofsson, M., and Viklander, M.: Applying climate model precipitation scenarios for urban hydrological assessment: A case study in Kalmar City, Sweden, Atmos. Res., 92, 364-375, doi:10.1016/j.atmosres.2009.01.015, 2009.

Prudhomme, C., Reynard, N., and Crooks, S.: Downscaling of global climate models for flood frequency analysis: Where are we now?, Hydrol. Process., 16, 1137-1150, 2002.

Setegn, S. G., Srinivasan, R., and Dargahi, B.: Hydrological Modelling in the Lake Tana Basin, Ethiopia Using SWAT Model, The Open Hydrology Journal., 2, 49-62, 2008.

Soliman, E. S. A., Sayed, M. A. A., Nour El-Din, M. M., and Samy, G.: Integration of NFS with Regional Climate Model to Simulate the Nile Basin Hydro-climatology, Nile Basin Water Engineering Scientific Magazine, 1, 75-85, 2008.

Strzepek, K. M. and Yates, D. N.: Economic and social adaptation to climate change impacts on water resources: a case study of Egypt, Water Resour. Development., 12, 229-244, 1996.

Wilby, R. L. and Wigley, T. M. L.: Precipitation predictors for downscaling: observed and General Circulation Model relationships, Int. J. Climatol., 20, 641-661, 2000.

Willems, P.: A time series tool to support the multi-criteria performance evaluation of rainfall-runoff models, Environ. Modell. Softw., 24, 311-321, 2009.

Willems, P.: VHM approach: transparent, step-wise and data mining based identification and calibration of parsimonious lumped conceptual rainfall-runoff models, J. Hydrol., revised, 2011.

Wu, X., Liang X.-Z., and Zhang, G. J.: Seasonal migration of ITCZ precipitation across the equator: Why can't GCMs simulate it?, Geophys. Res. Lett., 30, 1824-1827, doi:10.1029/2003GL017198, 2003.

Xu, C. Y., Widén, E., and Halldin, S.: Modelling hydrological consequences of climate change - Progress and challenges, Adv. Atmos. Sci., 22, 789-797, 2005.

Yates, D. N. and Strzepek, K. M.: Modelling economy-wide climate change impacts on Egypt: A case for an integrated approach, Environ. Model. Assess., 1, 119-135. 1996.

Yates, D. N. and Strzepek, K. M.: An assessment of integrated climate change impacts on the agricultural economy of Egypt, Climatic Change, 38, 261-287, 1998a.

Yates, D. N. and Strzepek, K. M.: Modelling the Nile Basin under climatic change, J. Hydrol. Eng., 3, 98-108, 1998b. 